\title{
INVESTIGATION OF INTELLIGENT CONTROLLER FOR NON-LINEAR SPHERICAL TANK SYSTEM
}

\author{
Ajith B. Singh ${ }^{1}$, J. Mownika ${ }^{2}$, S.K. Appoorvaa ${ }^{3}$, Gowtham Balasubramanian ${ }^{4}$ \\ P. Manju ${ }^{5}$, G.S. Monishaa ${ }^{6}$ \\ ${ }^{1}$ Assistant Professor, Department of Instrumentation and Control Engineering \\ 2,3,4,6 Undergraduate Students, Department of Instrumentation and Control Engineering \\ ${ }^{5}$ Head and Professor, Department of Instrumentation and Control Engineering \\ Sri Krishna College of Technology, Coimbatore.
}

\begin{abstract}
Spherical tanks are used to store fluids in many industries such as petrochemical, effluent treatment, and aerospace. Spherical tanks are used as they are highly resistant to internal pressure making them suitable for storing high-pressure materials due to their large volume, small weight, and strong load-bearing capacity. The spherical tanks have the lowest possible surface area to volume ratio. These tanks are preferred due to their capability of balancing pressure in and out of the tank and their ability to minimize the amount of heat that gets inside the tank wall. It is cost-effective when compared to other tanks. But, controlling the water level in the spherical tank is difficult and a highly challenging one. In this article, the aim is to stabilize the level of the spherical tank by using the PID and FUZZY logic controllers. By controlling nonlinear dynamic behavior, uncertainty, time-varying parameters, frequency disturbances and dead time, the stability of the tank is achieved. The mathematical modelling of the spherical system is obtained using first principles design and the stability of the model is analyzed using various techniques. Then, the simulation is done using MATLAB and the responses are obtained and compared for PID and FUZZY logic. Based on these comparisons made on the performance of the PID and FUZZY logic controllers, the results are concluded.
\end{abstract}

Keywords: Conventional PID, Fuzzy logic, Mathematical modelling, MATLAB.

\section{Introduction}

Nonlinear processes play a major role in the process control industries. Controlling a liquid level is important in all process industries [1]. If the water level increases in the tank, it may lead to the spillage, if the water level decreases, in the tank it may affect the operation in the process industries. So, the control of the tank level is an important process in every process industry. When compared to cylindrical tanks, spherical tanks are used in applications of outer space due to complete tank drainage. Several applications like nuclear material storage, water cooling systems, and storage of liquefied gases use spherical tanks because of the additional storage capacity, additional pressure in the system due to elevation with high rigidity and durability. A sphere is a very strong structure. There is no weaker point on the sphere due to its even distribution of stress [2]. The controlling of level, flow, temperature, and pressure are the challenging factors in all process-based industries. Chemical processes with nonlinearity cannot be controlled like a linear process due to their dynamic behavior. Nonlinear models are used in various industries for their accuracy over a wide range of operations [3]. The stability of the sphere makes it a challenging task. So, this system is stabilized with the conventional PID controller and to obtain a better stable output, intelligent controllers like the fuzzy logic controller is implemented.

Lakshmanan.M et al. had proposed research work on the entire operating region of the spherical tank system in chemical process industries to control the level of the fluid [4]. The mathematical modeling of the open-loop response for a spherical tank system is obtained. The Ziegler Nichols tuning (ZNT) method based on PID controller is compared with root locus techniques (RLT). The experimental results prove that the proposed system of Root locus technique (RLT) performs less index value than ZNT. Gowtham.T and Dr.M.Balaji proposed a review to control the liquid level in a spherical tank system, and tuning of nonlinear PI/PID controller in real-time [5]. The tuning of the PID controller is based on the Cohen coon method and the response is compared in terms of timedomain specifications. The results proved that the PI controller gives better peak time in all regions, and the PID controller provides desirable settling time, overshoot, and rise time for larger operation and gives better results than other controllers. N.Abinaya et al. proposed a fractional-order IMC - PID controller with a poor disturbance response and good set-point tracking which has the time- delay ratio for controlling nonlinear processes [6]. The fractional-order IMC is used to reduce the tuning parameters and time delay. The simulation results show that the fractional-order IMC - PID controller performs better than IMC - PID controller to achieve a steadystate value. Ka. Suriyaprabha and D.Rathikarani have proposed a system to control the level of the spherical tank 
using the LQR- PI controller [7]. LQR (Linear Quadratic Regulator) is the better method to obtain the closed-loop response. It stabilizes the response by controlling the feedback gain and gives better design performance. The optimization of the controller is done using Particle Swarm Optimization (PSO) and Genetic Algorithm (GA) methods. The response of the system is obtained using PSO based Linear Quadratic Regulator (LQR) - PI controller is compared with other controllers like GA based LQR PI and LQR PI controller. While comparing the performance of the response PSO based LQR - PI controller performs well and is used for time-varying processes in nonlinear systems. P.Deepa and R.Sivakumar have proposed the PI-Fuzzy controller with an adaptive neurofuzzy interface system for the control of liquid level in the spherical tank [8]. The closed-loop response of the PI-Fuzzy logic controller is compared with other controllers. The results of the responses have a better performance than other controllers with fewer errors and overshoot. S.J.Suji Prasad et al. have proposed the design of a Fuzzy PI controller for level control of a single tank spherical system [9]. The simulation of the responses is compared with the PID controller, and other controllers like I-PD, Fuzzy PID, Fuzzy I-PD. The results proved that the Fuzzy I-PD controller has better performance.

In this article, the transfer function of the proposed spherical tank system is obtained by the mathematical model derived from the system. The nonlinearity of the spherical tank can be overcome by controller techniques. The PID controllers are versatile, they are widely deployed in the process industries because of their feedback compensator structure, quite effective and reliable as they can respond to changes quickly [10]. Conventional PID controller with various tuning methods, and the response of the system based on timedomain specifications like IAE, ISE, and ITAE, error criteria like rise time, peak time, settling time, and overshoot are analyzed. However, the performance of the conventional PID controller is limited due to the nonlinearity in the proposed spherical tank system [10]. A Fuzzy logic controller is designed as an alternative for conventional controllers as it has a faster response and the complexity of the control is less. A Fuzzy controller suits better to control the level of the nonlinear spherical tank system due to their advancement in the characteristics of nonlinear structures where the conventional controller doesn't give satisfactory results [11]. The fuzzy logic controller based Mamdani method is designed for the proposed system for maintaining the liquid level in the process tank. The curve responses obtained from the simulation results of conventional PID and fuzzy logic controllers are compared and the results are obtained.

\section{PROCESS DESCRIPTION}

\section{A. EXPERIMENTAL SETUP:}

The proposed system consists of a spherical tank, flow transmitter, level transmitter, rotameter, pump, reservoir,
MODBUS, personal computer and hand valves. The spherical tank is made up of stainless steel and the valves are mounted at the bottom of the tank. The water stored in the reservoir is pumped to the spherical tank through the submerged pump. The water flow can be seen through the rotameter and the flow transmitter measures and sends the flow rate to the MODBUS in the form of 4-20 mA signal. The flow of fluid in the tank can be controlled by adjusting the float inside the rotameter.

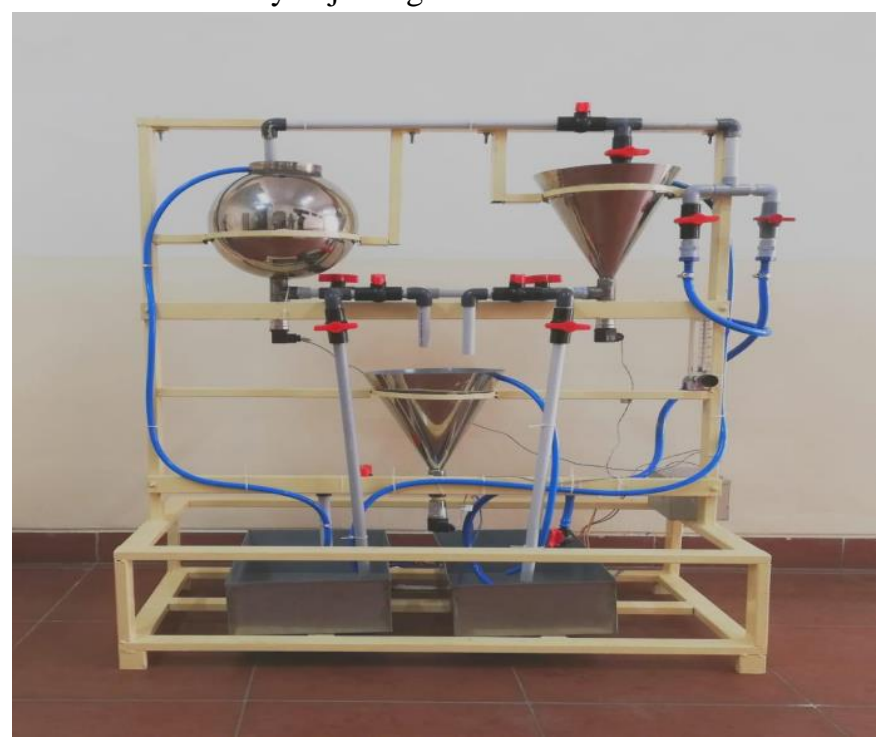

Figure1: Developed Experimental Setup

Then the level transmitter is used to measure the level in the tank by the pressure created in the tank and converted to a signal of $4-20 \mathrm{~mA}$ and transmits the signal to the MODBUS. MODBUS is used to transmit the information over electronic devices. So, the information about the flow rate of the fluid and level of the tank can be seen through the personal computer from the information obtained from MODBUS.

\begin{tabular}{|c|c|c|}
\hline S.no & $\begin{array}{l}\text { COMPONENTS } \\
\text { USED }\end{array}$ & SPECIFICATION \\
\hline 1. & Rotameter & $0-100 \mathrm{LPH}$ \\
\hline 2. & Level Transmitter & 100 millibar \\
\hline 3. & Flow Transmitter & $\begin{array}{l}\text { Adept Ecomag6420 } \\
(10-200 \mathrm{~mm})\end{array}$ \\
\hline 4. & MODBUS & Digi Rail 2A \\
\hline 5. & Submerged Pump & $\begin{array}{l}\text { Fractional } \quad \text { HP } \quad \text { Pump } \\
(0.05 \mathrm{HP})\end{array}$ \\
\hline 6. & Spherical Tank & $\begin{array}{l}10 \quad \text { inches }-(0.25 \mathrm{~m} \\
\text { diameter }) \\
\text { 7litres - capacity }\end{array}$ \\
\hline 7. & Reservoir & $0.25 \mathrm{~m} \times 0.1 \mathrm{~m} \times 0.37 \mathrm{~m}$ \\
\hline 8. & Hand Valve & 11 \\
\hline
\end{tabular}

Table 1: Components and its Specification

\section{B. SPHERICAL TANK:}

The spherical tank or otherwise called the Horton sphere spreads the pressure evenly across the tank. Spheres are the strongest shape, so they can hold the highest pressures. They minimize the heat that gets inside the tank because it has a low possible surface to 
volume ratio. Spherical tanks are highly resistant to highpressure liquids. These tanks are used as storage tanks in many process industries for the storage of fuels, cryogenic liquids, etc. [18].

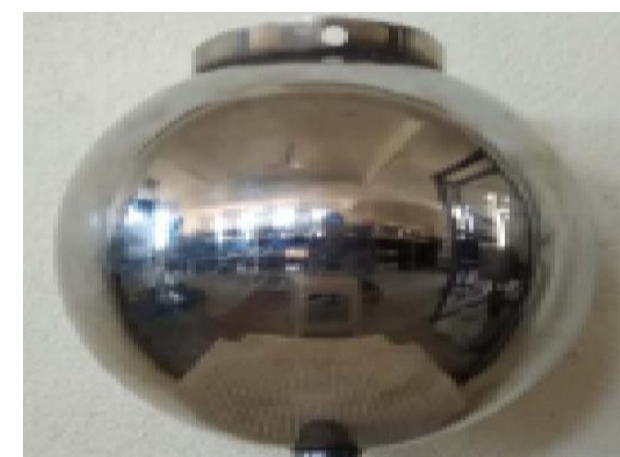

Figure 2: Spherical Tank

\begin{tabular}{|l|l|}
\hline Diameter $(\mathrm{d})$ & $25 \mathrm{~cm}(10$ inches $)$ \\
\hline Radius $®$ & $12.5 \mathrm{~cm}$ \\
\hline Volume of the sphere & 8.1 liters. \\
\hline
\end{tabular}

Table 2: Specification of Spherical Tank

\section{MATHEMATICAL MODELLING:}

Mathematical modelling is the process of developing a mathematical model of the proposed system which describes the process of a proposed system using mathematical concepts. The mathematical modelling of the proposed spherical tank system is based on its structure. It can be classified into two cases based on the change in the water level inside the spherical tank. At any instant, the level of the spherical tank is obtained by the mass balance equation indicated as

$\mathrm{V}=$ Volume of the tank,

$F_{\text {in }}=$ Inlet flow rate of the tank $\left(\mathrm{m}^{3} / \mathrm{min}\right)$

$\mathrm{F}_{\text {ou }}=$ Outlet flow rate of the tank $\left(\mathrm{m}^{3} / \mathrm{min}\right)$

$\mathrm{R}=$ Radius of the tank $(\mathrm{cm})$

$\mathrm{H}=$ Height of the tank $(\mathrm{cm})$

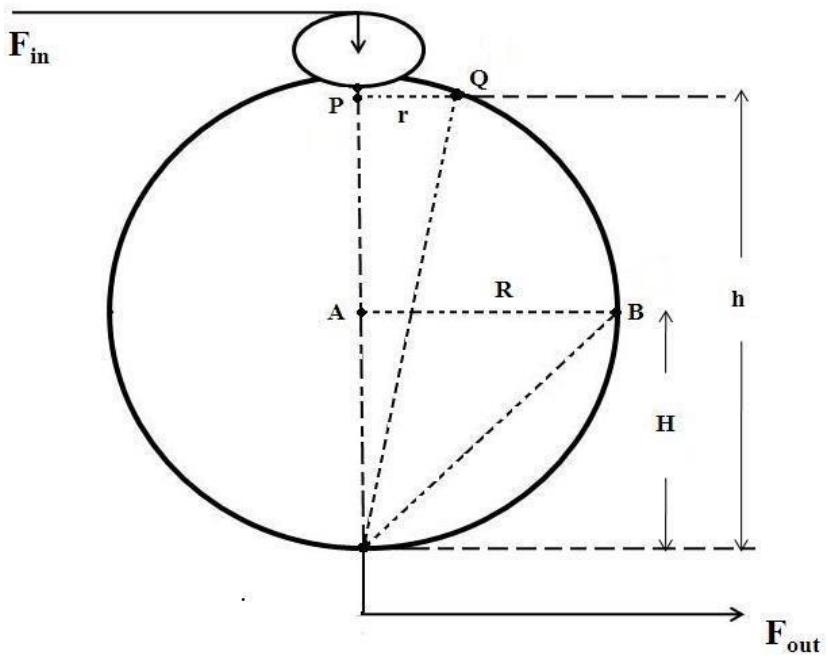

Figure 3: Cross sectional view of Spherical Tank
CASE 1: When height $(\mathrm{H})$ of the liquid column is equal to the radius $(\mathrm{R})$ of the spherical tank

This case applies when the liquid level of the tank and radius of the tank are equal. Therefore, considering the radius is equal to height $(\mathrm{R}=\mathrm{H})$.

The first order differential equation for the non-linear spherical tank system is given by the equation,

Where

$$
\begin{array}{r}
\frac{d V}{d t}=F_{\text {in }}-F_{\text {out }} \\
V=\frac{4}{3} \pi R^{3}
\end{array}
$$

At any instant, the water level in the STS is obtained by a mass-balance equation which is given by,

$$
F_{\text {in }}-F_{\text {out }}=A h
$$

$\mathrm{A}=$ Cross sectional area

$\mathrm{H}=$ Overall height of the tank

$$
\frac{d V}{d t}=A \frac{d h}{d t}=F_{\text {in }}-F_{\text {out }}
$$

Substituting the equation (3) and $A=4 \pi R^{2}$ in equation (4)

$$
F_{\text {in }}-F_{\text {out }}=\frac{1}{3} A R=\frac{1}{3} A h
$$

Considering $R=h$

$$
R=\frac{r h}{H}
$$

Assuming the $\mathrm{F}_{\text {out }}$,

$F_{\text {out }}$ is linearly related to ' $h$ ' through ' $R_{\mathrm{v}}$ '.

$$
\begin{gathered}
F_{i n}(s)=A S(S)+\frac{H(s)}{R_{v}} \\
\frac{H(s)}{F_{\text {in }}(s)}=\frac{K}{1+\tau S}
\end{gathered}
$$$$
\text { Considering, } R_{v}=K, \tau=A R_{v}
$$

CASE 2: When the height $(\mathrm{H})$ of the liquid column is greater or lesser than radius $(\mathrm{R})$ of the spherical tank

This case is implemented when the liquid level is not equal to the radius. Therefore, the liquid level of the system is greater than or lesser than the radius of the tank $(\mathrm{R}<\mathrm{H}$ or $\mathrm{R}>\mathrm{H})$.

The tank with the angle $\theta$,

$$
\tan \theta=\frac{r}{h}=\frac{R}{H}
$$

Volume of the tank,

$$
V=A h
$$

Differentiating the equation,

$$
\frac{d V}{d t}=\left[A \frac{d h}{d t}+h \frac{d A}{d t}\right]
$$

The first order differential equation for the nonlinear spherical 
tank system is given by the equation,

$$
F_{\text {in }}-F_{\text {out }}=\frac{d V}{d t}
$$

Substituting the equation (10) in equation (11),

$$
\begin{gathered}
F_{\text {in }}-F_{\text {out }}=\frac{d h}{d t}\left[A+h^{2} 8 \pi\left(\frac{R}{H}\right)^{2}\right] \\
\frac{d h}{d t}=\frac{F_{\text {in }}}{12 \pi\left(\frac{R}{H}\right)^{2} h^{2}}-\frac{K \sqrt{H}}{12 \pi\left(\frac{R}{H}\right)^{2} h^{2}}
\end{gathered}
$$

Substituting the $\alpha$ and $\beta$ value in equation (6),

$$
\frac{d h}{d t}=\alpha F_{i n} h^{-2}-\beta h^{\frac{-3}{2}}
$$

For linearizing $F_{\mathrm{in}} h^{-2}$ and $h^{\frac{-3}{2}}$ in equation (7),

$F\left(h, F_{\text {in }}\right)=F\left(h_{s}, F_{\text {ins } s}\right)-2 F_{\text {in }} h_{s}^{-3}(h-$

$\left.h_{s}\right)+h_{s}{ }^{-2}\left(F-F_{\text {ins }}\right)$

At initial and steady state condition, substituting the y value and $U$ value,

$$
\frac{d y}{d t}=\left[\alpha\left[-2 F_{i n} h_{s}^{-3} y+h_{s}^{-2} U\right]+\frac{3}{2} h^{\frac{-5}{z}} y\right]
$$

The transfer function of the system is given as,

$$
\begin{aligned}
\frac{Y(s)}{U(s)} & =\frac{c}{\tau S+1} \\
\qquad & =\frac{2 \alpha}{\beta} h_{s^{2}}{ }^{\frac{5}{2}} \quad c=\frac{2 \alpha}{\beta} h_{s^{2}}
\end{aligned}
$$

\section{A. PID CONTROLLER:}

\section{CONTROLLER DESCRIPTION}

A Proportional Integral Derivative controller commonly known as the PID controller is a control feedback mechanism widely used in industrial control applications for its simplicity and effectiveness. The PID controller had survived in a satisfactory way with a change of technology from an analog to a digital control system. A process of adjusting the control parameters like $\mathrm{K}_{\mathrm{p}}, \mathrm{K}_{\mathrm{i}}, \mathrm{K}_{\mathrm{d}}$ is controller tuning to reach optimum values and obtain desired output is controller tuning which is essential in maintaining the stability of the proposed system $[10,12,18]$.

These three terms comprise and gives a PID controller output equation is written as,

$$
u(t)=K_{p} e(t)+K_{I} \int_{0}^{t} e(\tau) d \tau+K_{D} \frac{d e(t)}{d t}
$$

The following are the most commonly used PID controller tuning methods which are used to tune the proposed spherical tank system

1. Cohen Coon Method - Based on the process reaction curve the controller is tuned.
2. Ziegler - Nichols Method: Based on the values of ultimate gain and ultimate period the controller is tuned.

3. Tyreus Luyben Method

4. Ciancone - Marlin Method

The PID controller can't give a solution to all problems. The process is time-variant and complex with non-linearity and its delay time. To operate the control system in a better way with artificial intelligence, a fuzzy logic controller is implemented. The fuzzy logic is one of the fast-growing techniques which gives better support for translating the procedures of control action into their numerical algorithm. In the PID controller, the system is tuned to obtain the desirable output. This method can be replaced by a fuzzy controller and can give a better response for the proposed system.

\section{B. FUZZY LOGIC CONTROLLER:}

The Fuzzy logic was established by L.A. Zadel in the year 1965. He taught that other conventional controllers focus on precision value than easy and efficient controlling methods. Whereas in Fuzzy logic he implemented a certain set of conditions or procedures for each and every element [12].

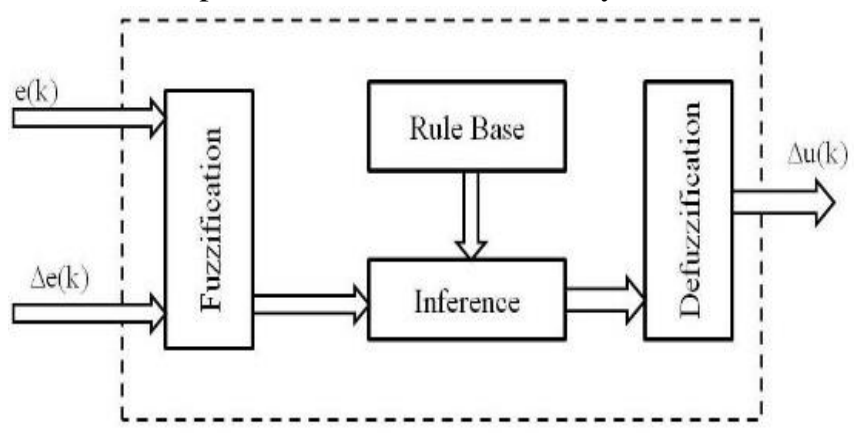

Figure 4: Fuzzy Logic Controller

Figure 4 represents the block diagram of fuzzy logic controller. The inputs (error and derivative of error) are fuzzified i.e., crisp numbers are converted into fuzzy sets. Rule base stores the rules provided by the user. The rules are represented in the form of a table called fuzzy access memory table (Table 3). Inference block is used to compare the inputs with the rules and the corresponding output is obtained. In the defuzzification module, the fuzzy output is converted into crisp values.

\section{Fuzzification Module:}

After identifying the state variable, it is passed through the block to fuzzify the input. The fuzzy based rule works on linguistic variables that convert numerical inputs to fuzzy linguistic variables and this process is called fuzzification.

\section{Defuzzification:}

It is the converse form of fuzzification. The linguistic variable is the output obtained from the fuzzy logic controller. It delivers quantifiable results in fuzzy form. The main disadvantage of the method is that the data get lost.

Fuzzy based Rule and Interfacing engine:

The fuzzy interface is of two methods: Mamdani and Sugeno. 


\section{Mamdani Method:}

This method is commonly used in fuzzy logic and it is the first control system using fuzzy logic control. The singleton output membership function is defined as the single spike in the output as the output membership. This method is used to find the centroid of two dimensions of the membership function.

\section{Sugeno Method:}

The Sugeno method is the same as the Mamdani method. It is used to model the system interface and obtain the output either in linear or constant. This system is more effective in calculating and controlling. It may improve the linear technique used to optimize the parameters and their works.

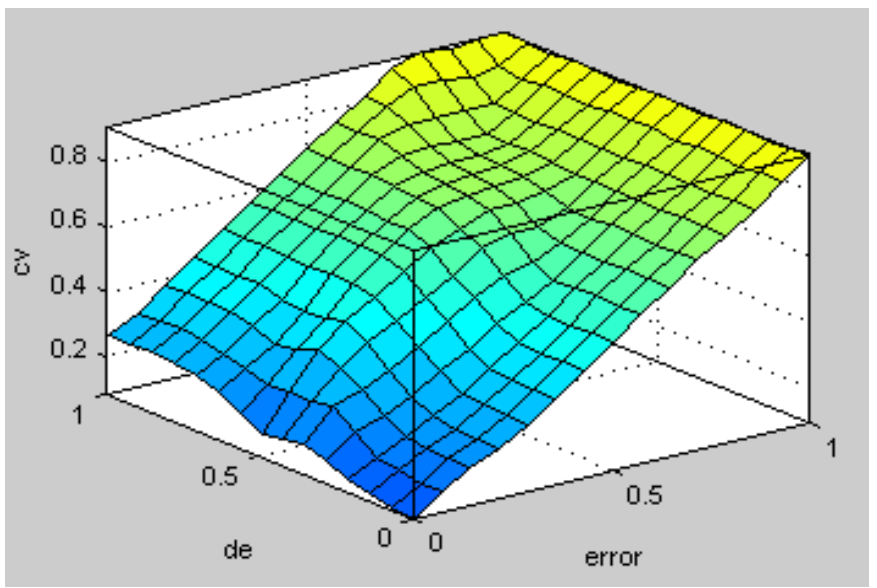

Figure 5: Surface View
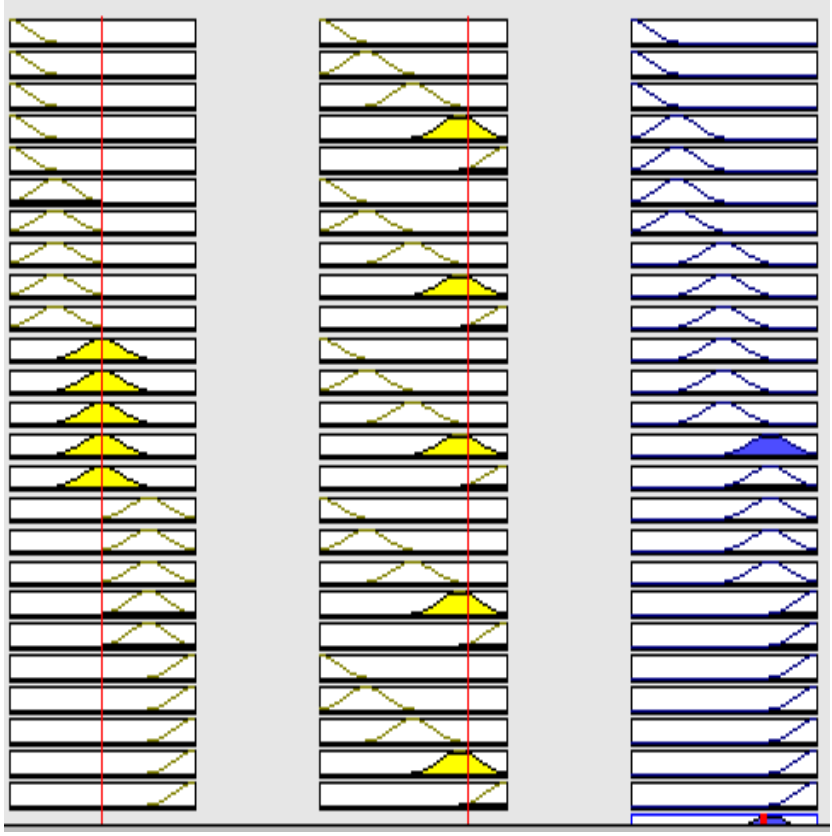

Figure 6: View of Rules

The two input variables are error (e) and derivative of error (de) and the output variable is control variable (cv). The linguistic variables are VL (very low), L (low), M (medium), $\mathrm{H}$ (high), VH (very high). The fuzzy access memory table (FAM table) is an easy way to represent the rules in the form of a table. It shows the output of different input combinations of the system. Figure 5 represents the surface view and Figure 6 represents the rule view. As their name indicates, they both are read only tools. Surface view is a $3 \mathrm{D}$ representation of dependency of output on inputs. Rule view is used to view the detailed behavior of fuzzy inference system[12].

\section{RESULTS AND DISCUSSION}

The stability analysis for the system is done by various methods like bode plot. Nyquist plot, root locus technique. Then the responses of PID and FUZZY are obtained and finally the results are compared. The above procedure is done for both cases (Fixed area and change in area) separately and the results are concluded.

CASE 1: When height $(\mathrm{H})$ of the liquid column is equal to the radius $(\mathrm{R})$ of the spherical tank

$\frac{H(s)}{F_{\text {in }}(s)}=\frac{0.523}{1+1027 \mathrm{~s}}$

Bode plot being the most important method for stability analysis is based on frequency domain analysis.

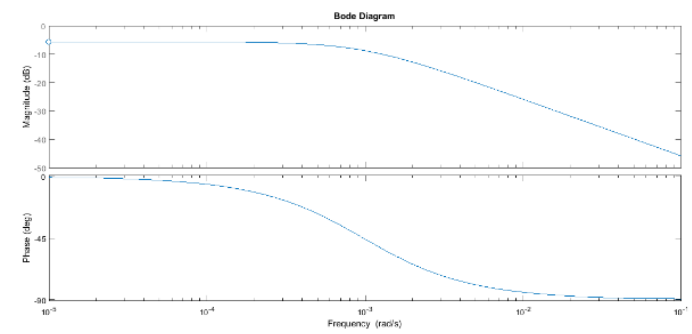

Figure 7: Response of Bode Plot

From the magnitude and phase plot in the graph, the gain margin and phase margin value are infinity which indicates that the system is stable for all conditions.

Nyquist plots are used to find the stability margins which helps to find our system whether it is stable or not.

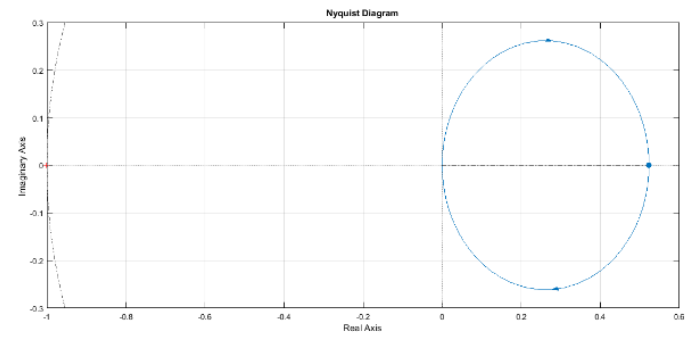

\section{Figure 8: Response of Nyquist Plot}

The gain margin and phase margin values are found to be infinity. These values from the graph helps us to conclude that the system will be stable in all conditions.

In root locus technique, based on the position of the roots in the S-plane, the stability is determined. 


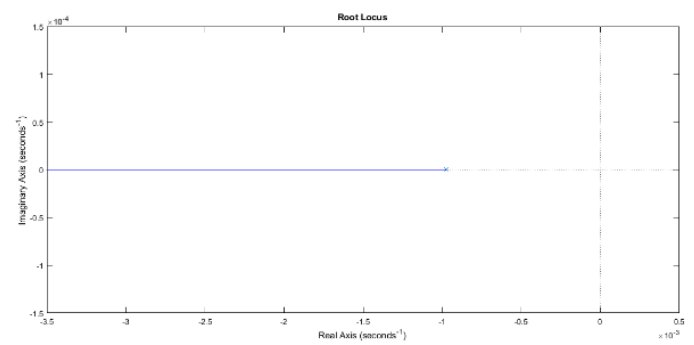

Figure 9: Response of Root Locus Technique

The graph represents the response of root locus technique where the pole lies on the left half of the S-Plane. The pole on the left half indicates that the system is stable.

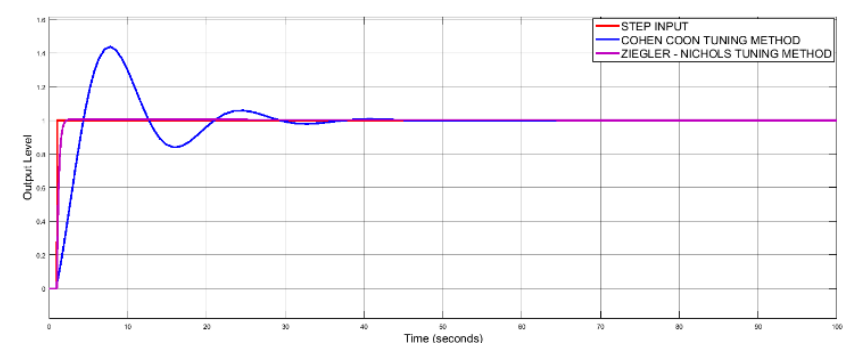

Figure 10: Response of Different Tuning Methods

The above graph represents the comparison of different tuning methods. The PID controller tuned by various tuning methods are compared with their time domain responses obtained from the graph and are tabulated below (Table 3). From Table 3, the rise time and settling time for Ziegler - Nichols tuning method is quite faster when compared with other PID tuning methods. The tuning methods like Cohen coon, Tyreus Luyben and Ciancone has overshoot whereas Ziegler - Nichols tuning method has no overshoot. From the responses obtained from the graph and based on the comparisons made between different PID tuning methods, it can be concluded that the Ziegler - Nichols tuning method shows a good stability rate over other PID tuning methods.

\begin{tabular}{|l|l|l|l|l|}
\hline $\begin{array}{l}\text { PID } \\
\text { TUNING } \\
\text { METHODS }\end{array}$ & $\begin{array}{l}\text { Cohen - } \\
\text { Coon }\end{array}$ & $\begin{array}{l}\text { Ziegler } \\
\text { Nichols }\end{array}$ & $\begin{array}{l}\text { Tyreus } \\
\text { Luyben }\end{array}$ & Ciancone \\
\hline $\begin{array}{l}\text { Settling } \\
\text { Time } \\
\text { (seconds) }\end{array}$ & $\begin{array}{l}4.18^{*} \mathrm{e}^{\wedge} \\
03\end{array}$ & 0.904 & $\begin{array}{l}6.1 * \mathrm{e}^{\wedge} 0 \\
3\end{array}$ & $\begin{array}{l}6.17^{*} \mathrm{e}^{\wedge} 0 \\
3\end{array}$ \\
\hline $\begin{array}{l}\text { Peak } \\
\text { Overshoot }\end{array}$ & 1.05 & 0 & 1.98 & 1.93 \\
\hline $\begin{array}{l}\text { Overshoot } \\
(\%)\end{array}$ & 5.32 & 0 & 97.6 & 92.9 \\
\hline $\begin{array}{l}\text { Rise Time } \\
\text { (seconds) }\end{array}$ & $\begin{array}{l}1.29 * \mathrm{e}^{\wedge} \\
03\end{array}$ & 0.534 & 12.5 & 0.393 \\
\hline
\end{tabular}

Table 3: Comparisons of Tuning Parameter of PID Controller of Time Domain Analysis

\begin{tabular}{|l|l|l|l|}
\hline $\begin{array}{l}\text { ERROR } \\
\text { CRITERIA } \rightarrow\end{array}$ & $\begin{array}{l}\text { Integral } \\
\text { Square } \\
\text { Error } \\
\text { (ISE) }\end{array}$ & $\begin{array}{l}\text { Integral } \\
\text { Absolute } \\
\text { Error }\end{array}$ & $\begin{array}{l}\text { Integral } \\
\text { Time } \\
\text { Absolute } \\
\text { (IAE) }\end{array}$ \\
$\begin{array}{l}\text { Error } \\
\text { (ITAE) }\end{array}$ \\
$\begin{array}{l}\text { CONTOLLER } \\
\text { PID - Coon }\end{array}$ & 5.512 & 7.043 & 38.69 \\
\hline $\begin{array}{l}\text { Ziegler -Nichols } \\
\text { PID }\end{array}$ & 0.1192 & 0.2832 & 0.5735 \\
\hline $\begin{array}{l}\text { Tyreus - Luyben } \\
\text { PID }\end{array}$ & 7.447 & 8.153 & 42.98 \\
\hline $\begin{array}{l}\text { Ciancone PID } \\
\text { controller }\end{array}$ & 8.795 & 8.897 & 48.72 \\
\hline
\end{tabular}

Table 4: Error Criteria for PID Tuning Methods and Fuzzy Logic Controllers

The PID controller tuned by various tuning methods and fuzzy logic controller are compared with their objective function from the major error criterion techniques of Integral Square Error (ISE), Integral Absolute Error (IAE) and Integral Time Absolute Error (ITAE). The error analysis for the proposed system is done for the identification of better tuning method. From the Table 4, the error values of Ziegler - Nichols PID tuning method is very much reduced. This shows that the Ziegler - Nichols tuning method has better response over other tuning methods.

CASE 2: When the height $(\mathrm{H})$ of the liquid column is greater or lesser than radius $(\mathrm{R})$ of the spherical tank. The transfer function of the tank is given by,

$\frac{Y(s)}{U(s)}=\frac{11.49}{8772 s+1}$

An important method which gives us information about the stability analysis of a system is bode plot. 


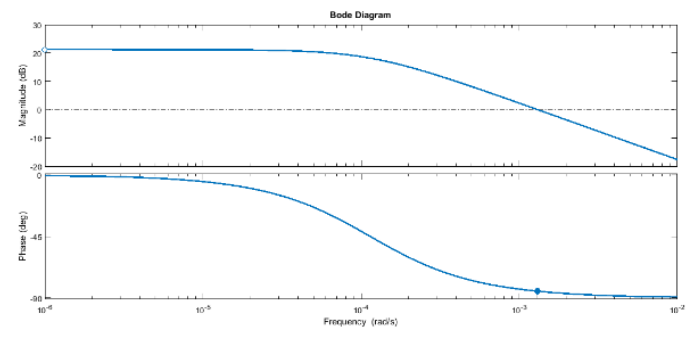

Figure 11: Response of Bode Plot

The value of gain margin and phase margin obtained from the graph is infinity and 95. These two values indicate that the system is stable under all conditions.

Nyquist plot provides the stability margin of the system.

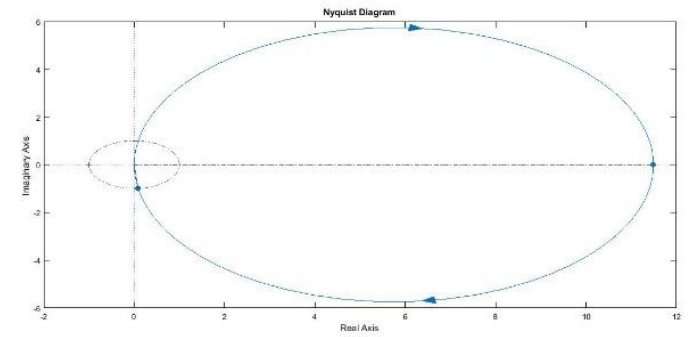

Figure 12: Response of Nyquist Plot

The gain margin is infinity and phase margin, gain crossover frequency is 95 and 0.0013 , helps us to conclude the stability of the system. These values imply that the system is stable.

The position of the roots determines the stability of the system in root locus technique.

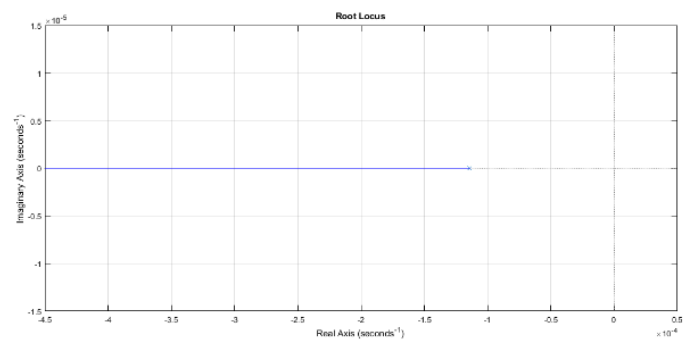

Figure 13: Response of Root Locus Technique

From the graph, the value of the pole -1.2 lies on the left half of the $\mathrm{S}$ - Plane indicating the system to be stable.

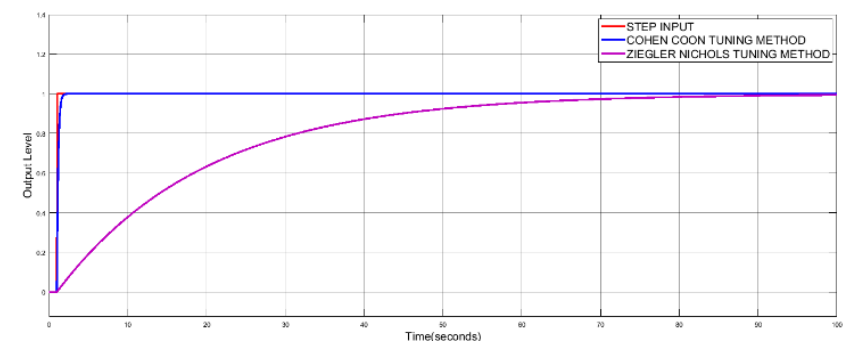

Figure 14: Response of Different Tuning Methods

The above graph represents a comparison of different tuning methods. The PID controller tuned by various tuning methods are compared with their time domain responses obtained from the graph and are tabulated below (Table 5). From Table 5, the rise time and settling time for Cohen coon tuning method is quite faster when compared with other PID tuning methods. Both the Cohen coon and Ziegler - Nichols tuning methods has no overshoot whereas the other tuning methods have overshoot. From the responses obtained from the graph and based on the comparisons made between different PID tuning methods, it can be concluded that the Cohen - coon tuning method shows a good stability rate over other PID tuning methods.

\begin{tabular}{|l|l|l|l|l|}
\hline $\begin{array}{l}\text { PID } \\
\text { TUNING } \\
\text { METHOD }\end{array}$ & $\begin{array}{l}\text { Cohen - } \\
\text { Coon }\end{array}$ & $\begin{array}{l}\text { Ziegler } \\
\text { Nichols }\end{array}$ & $\begin{array}{l}\text { Tyreus } \\
\text { Luyben }\end{array}$ & $\begin{array}{l}\text { Ciancon } \\
\mathrm{e}\end{array}$ \\
\hline $\begin{array}{l}\text { Settling } \\
\text { Time } \\
\text { (seconds) }\end{array}$ & 0.653 & 74.9 & $\begin{array}{l}2.18 * \\
\mathrm{e}^{\wedge} 04\end{array}$ & $\begin{array}{l}2.23 \\
\mathrm{e}^{\wedge} 04\end{array}$ \\
\hline $\begin{array}{l}\text { Peak } \\
\text { Overshoot }\end{array}$ & 0 & 0 & 1.99 & 1.99 \\
\hline $\begin{array}{l}\text { Overshoot } \\
\text { (\%) }\end{array}$ & 0 & 0 & 99.5 & 98.9 \\
\hline $\begin{array}{l}\text { Rise Time } \\
\text { (seconds) }\end{array}$ & 0.367 & 41.7 & 5.86 & 18.3 \\
\hline
\end{tabular}

Table 5: Comparisons of Tuning Parameter of PID of Time Domain Analysis

\begin{tabular}{|c|c|c|c|}
\hline $\begin{array}{l}\text { ERROR } \\
\text { CRITERIA } \rightarrow \\
\text { CONTROLLER } \\
\downarrow\end{array}$ & $\begin{array}{l}\text { Integral } \\
\text { Square } \\
\text { Error } \\
\text { (ISE) }\end{array}$ & $\begin{array}{l}\text { Integral } \\
\text { Absolute } \\
\text { Error } \\
\text { (IAE) }\end{array}$ & $\begin{array}{l}\text { Integral } \\
\text { Time } \\
\text { Absolute } \\
\text { Error } \\
\text { (ITAE) }\end{array}$ \\
\hline $\begin{array}{l}\text { Cohen - Coon } \\
\text { PID }\end{array}$ & 0.0835 & 0.16712 & 0.1958 \\
\hline $\begin{array}{ll}\text { Ziegler } & \text {-Nichols } \\
\text { PID } & \end{array}$ & 5.809 & 7.164 & 36.86 \\
\hline $\begin{array}{l}\text { Tyreus - Luyben } \\
\text { PID }\end{array}$ & 4.39 & 5.607 & 23.61 \\
\hline Ciancone PID & 8.201 & 8.584 & 46.32 \\
\hline $\begin{array}{ll}\text { Fuzzy } & \text { logic } \\
\text { controller } & \end{array}$ & 424.8 & 892.2 & $1 * \mathrm{e}^{\wedge} 06$ \\
\hline
\end{tabular}

Table 6: Error Criteria for PID Tuning Methods and Fuzzy Logic Controllers

The PID controller tuned by various tuning methods and fuzzy logic controller are compared with their objective function from the major error criterion techniques of Integral Square Error (ISE), 
Integral Absolute Error (IAE) and Integral Time Absolute Error (ITAE). The error analysis for the proposed system is done for the identification of better tuning method. From the Table 6, the error values of Cohen coon PID tuning method is very much reduced. This shows that the Cohen - coon tuning method has better response over other tuning methods.

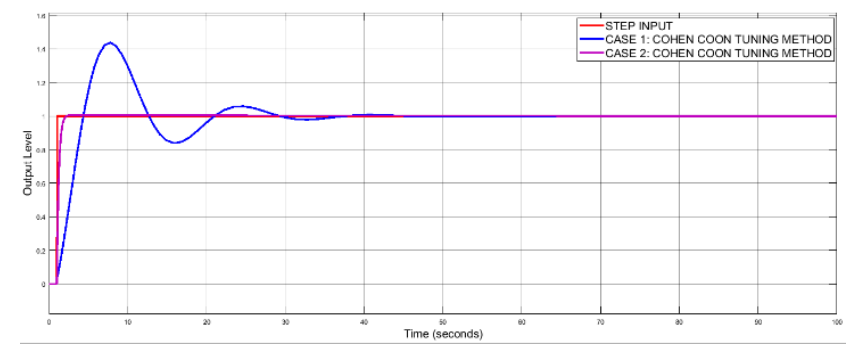

Figure 15: Responses of PID Controller

The above graph represents the comparison of responses of PID controller for both cases (Fixed area and Change in area). It can be seen that one of the cases shows overshoot and then gradually it becomes stable. But the other one does not have any overshoot; it gets stable in a smooth way.

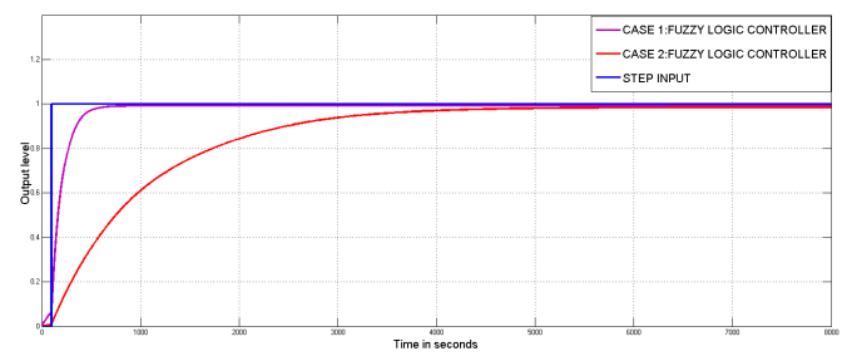

Figure 16: Responses of Fuzzy Logic Controller

The above figure represents the responses of fuzzy logic controller in both the cases (Fixed area and change in area). Both the responses are getting stable in a smooth way but the time taken to become stable is faster in fixed area than the change in area[12].

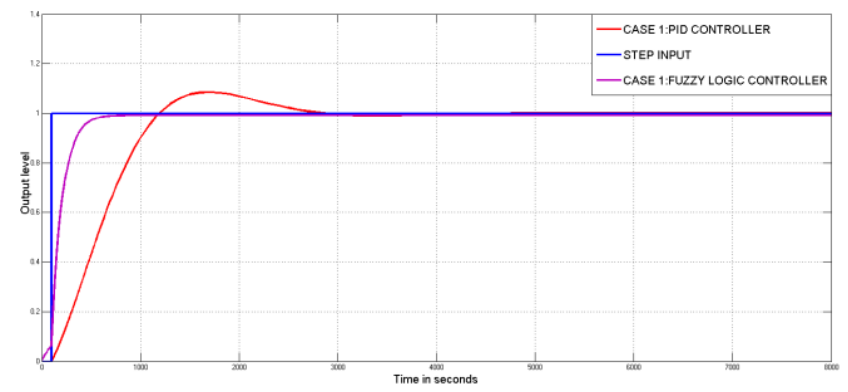

Figure 17: Comparison of PID And Fuzzy (Case 1)

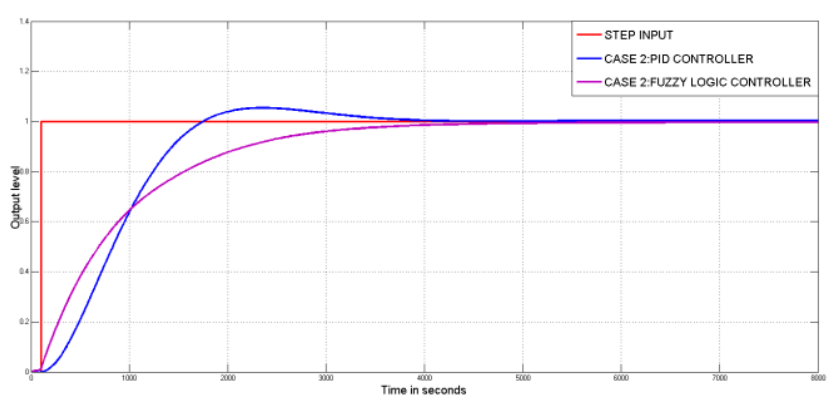

Figure 18: Comparison of PID And Fuzzy (Case 2)

Both the PID and fuzzy responses are compared to find the better system response. The fuzzy response has no overshoot and the system becomes stable even without any disturbances like overshoot in the PID. Fuzzy logic controller shows a faster settling time than the conventional PID controller. So, it can be seen that fuzzy logic shows better response than PID.

\section{V.CONCLUSION}

In this paper, the mathematical modelling of the proposed spherical tank system is obtained. Stability of the system is analyzed using various techniques and the responses of PID and FUZZY logic are obtained. Then, both conventional PID and fuzzy logic controllers are compared for better performance. Based on the performance analysis, it can be concluded that the FUZZY logic controller shows better performance than the conventional PID controller.

In the future, this system will be upgraded with a nonlinear conical tank system in an interacting mode. Conventional PID controllers and fuzzy logic controllers can be implemented and the performance of the system can be analyzed and the results are concluded.

\section{REFERENCES}

[1] A. Ganesh Ram and S. Abraham Lincoln, "Real time implementation of fuzzy based adaptive PI controller for a spherical tank system," Int. J. Simul. Syst. Sci. Technol., vol. 14, no. 6, pp. 1-8, 2013, doi: 10.5013/IJSSST.a.14.06.01.

[2] B. J. Raj and P. S. H. Jose, "Fuzzy logic based PID controller for a non linear spherical tank system,” Int. J. Eng. Res. Technol., vol. 3, no. 2, pp. 1867-1870, 2014.

[3] S. Babushanmugham, "Level Control of a Non-Linear Spherical Tank System using GA based Controller," Int. J. Res. Appl. Sci. Eng. Technol., vol. 6, no. 3, pp. 21962203, 2018, doi: 10.22214/ijraset.2018.3347.

[4] M. Lakshmanan, K. Chitra, V. Kamatchi Kannan, and S. Srinivasan, "Online Tuning of PI Controller for Spherical Tank System Using Root Locus Technique with Regulatory Operation,” Proc. 2nd Int. Conf. Inven. Res. Comput. Appl. ICIRCA 2020, pp. 1035-1041, 2020, doi: 10.1109/ICIRCA48905.2020.9182957.

[5] T. Gowtham and D. M. Balaji, "Control Of Non Linear Spherical Tank Process With PI-PID Controllers - A Review," 
Gowtham.T J. Eng. Res. Appl., vol. 8, no. 9, pp. 28-34, 2018, doi: 10.9790/9622-0809032834.

[6] N. Abinaya, A. V. D. Priya, J. Yazhini, and K. M. Nandhini, "Fractional Order IMC-PID Controller Design for Non-Linear System,” no. 2011, pp. 1-7, 2018, doi: 10.17148/IJIREEICE/611.

[7] K. Suriyaprabha and D. Rathikarani, "LQR based Control Strategies for a Spherical Tank Level Process," Int. J. Innov. Technol. Explor. Eng., vol. 9, no. 4, pp. 2637-2641, 2020, doi: 10.35940/ijitee.d1578.029420.

[8] P. Deepa and R. Sivakumar, "Synthesis of heuristic control strategies for liquid level control in spherical tank," Proc. 3rd IEEE Int. Conf. Adv. Electr. Electron. Information, Commun. Bio-Informatics, AEEICB 2017, no. $10, \quad$ pp. 316-319, 2017, doi: 10.1109/AEEICB.2017.7972323.

[9] S. Vinodhini, S. J. Suji Prasad, B. Meenakshipriya, and B. Venkatesan, "Design of fuzzy I-PD controller for level control of spherical tank system," Proc. 2017 Int. Conf. Innov. Information, Embed. Commun. Syst. ICIIECS 2017, vol. 2018-Janua, pp. 1-5, 2018, doi: 10.1109/ICIIECS.2017.8276046.

[10] Sakthivel.G, T.S.Anandhi, and S.P.Natarajan, "Design of Fuzzy Logic Controller for a Spherical tank system and its ABSTRACT," Int. J. Eng. Res. Appl., vol. 1, no. 3, pp. 934-940.

[11]B. Mondal, Am. Billaha, B. Roy, and R. Saha, "Performance Comparison of Conventional PID and Fuzzy Logic Controller in the Field of over headed Water Level Control System Transducer design and development View project Performance Comparison of Conventional PID and Fuzzy Logic Controller in the Field,” Int. J. Comput. Sci. Eng., vol. 4, no. 6, pp. 76-81, 2016, [Online]. Available: https://www.researchgate.net/publication/307638939.

[12] A. Anie Selva Jothi, B. Ajith Singh, J. Jeyapadmini, and S. Sheebarani, "Fuzzified control of deaerator system in power plant \& comparative analysis with pid control scheme," J. Adv. Res. Dyn. Control Syst., vol. 11, no. 1 Special Issue, pp. 923-931, 2019. 